\title{
Memórias do Trabalho da Leveza: as Experiências dos Mestres e Mestras nas Artes de Miriti (Abaetetuba-PA) ${ }^{1}$
}

\author{
Memorias del Trabajo de la Leveza: las Experiencias de los Maestros y \\ Maestros en las Artes de Miriti (Abaetetuba-PA)
}

\author{
Memories of the Work of Lightness: The Experiences of Masters in the Arts \\ of Miriti (Abaetetuba-PA)
}

\section{Claudete do Socorro Quaresma da Silva²}

\begin{abstract}
Resumo
O presente trabalho analisa experiências vividas em memórias construídas e narradas por mestres e mestras da artesania do miriti do município de Abaetetuba, no Pará, os quais transformam partes da folha e do fruto da palmeira Mauritia flexuosa, popular miritizeiro, em brinquedos, cestarias, bijuterias, chapéus e outros objetos artísticos e artesanais. Detentores de saberes de um ofício tradicional na Amazônia Brasileira, homens e mulheres em circuitos de tradições orais e culturais reproduzem e traduzem cotidianamente relações de trabalho, sociabilidades, conflitos e disputas nas diversas esferas da vida. Abaetetuba emerge como lócus da pesquisa porque a história da cidade se confunde com a própria história da produção, comercialização e circulação dos famosos brinquedos de miriti. Ali se constituiu um dos centros de produção dos brinquedos de miriti mais conhecidos da Amazônia Oriental, registrado como patrimônio cultural do Estado do Pará. Neste texto, cruzando a Etnografia com a História Oral enfatizam-se análises a respeito das relações constituídas entre os mestres e mestras da arte em miriti e o ente público Municipal, Estadual e Federal percebidas nas interpretações do vivido narradas pelos (as) mestres (as). Visa construir interlocuções entre as narrativas dos (as) artesãos (ãs) e a proposta epistemológica dos estudos culturais e pós-coloniais no que tange a dialética da luta cultural e a leitura do processo histórico a partir da experiência cotidiana dos diferentes agentes e suas relações de confrontações, entrelaçamentos, negociações e empréstimos recíprocos. Por fim, assinala a importância de se compreender que na cultura a experiência dos diferentes sujeitos, ou grupos sociais, ou instituições onde estes agentes se encontram, travam relações de troca e sociabilidade, força e poder no âmbito das práticas sociais construídas no dia a dia por homens e mulheres que fazem a história acontecer e movimentam o processo histórico local e regional.
\end{abstract}

Palavras-Chave: Amazônia; Memória; Miriti; Trabalho;

\section{Resumen}

El presente trabajo analiza experiencias vividas en memorias construidas y narradas por maestros y maestras de la artesanía del miriti del municipio de Abaetetuba, en el Pará, los cuales transforman partes de la hoja y del fruto de la palmera Mauritia flexuosa, popular miritizeiro, en juguetes, cestas, bisutería, sombreros y otros objetos artísticos y artesanales. Los hombres y mujeres en circuitos de tradiciones orales y culturales reproducen y traducen cotidianamente relaciones de trabajo, sociabilidades, conflictos y disputas en las diversas esferas de la vida. Abaetetuba emerge como locus de la investigación porque la historia de la ciudad se confunde con la propia historia de la producción, comercialización y circulación de los famosos juguetes de miriti. En este texto, cruzando la Etnografía con la Historia Oral se enfatizan análisis acerca de las relaciones constituidas entre los maestros y el público, las maestras del arte en miriti y el ente público Municipal, Estadual y Federal percibidas en las interpretaciones de lo vivido narradas por los (as) maestros (as). Se pretende construir interlocuciones entre las narrativas de los artesanos y la propuesta epistemológica de los estudios culturales y postcoloniales en lo que se refiere a la dialéctica de la lucha cultural y la lectura del proceso histórico a partir de la experiencia

\footnotetext{
${ }^{1}$ Artigo apresentado no Simpósio Temático (EXPERIÊNCIAS ESTÉTICAS COM A ARTE ENQUANTO CULTURA) durante o II Seminário Latino-Americano de Estudos em Cultura - SEMLACult em Foz do Iguaçu/PR, Brasil, 2018.

${ }^{2}$ Mestra em Educação / Doutoranda em História Social da Amazônia; Universidade Federal do Pará - UFPA; Belém, Pará, Brasil; claudasilva21@gmail.com.
} 
cotidiana de los diferentes agentes y sus relaciones de confrontaciones, entrelazamientos, negociaciones y préstamos recíprocos. Por último, señala la importancia de comprender que en la cultura la experiencia de los diferentes sujetos, o grupos sociales, o instituciones donde estos agentes se encuentran, traban relaciones de intercambio y sociabilidad, fuerza y poder en el ámbito de las prácticas sociales construidas en el día a día por hombres y mujeres que hacen la historia suceder y mueven el proceso histórico local y regional.

Palabras clave: Amazonia; memoria; miriti; trabajar

\begin{abstract}
The present work analyze experiences lived in memories built and narrated by masters artisans of the miriti of the municipality of Abaetetuba, in Pará, which transform parts of the leaf and the fruit of Mauritia flexuosa palm, popular miritizeiro, in toys, baskets, imitation jewelry, hats and other artistic and craft objects. Knowledge holders of a traditional craft in the Brazilian Amazon, men and women in circuits of oral and cultural traditions reproduce and translate everyday working relationships, sociabilities, conflicts and disputes in the various spheres of life. Abaetetuba emerges as a locus of research because the history of the city is confused with the very history of the production, marketing and circulation of the famous miriti toys. There, one of the centers of production of the best-known miriti toys of Eastern Amazonia, registered as cultural patrimony of the State of Pará was constituted. In this text, crossing the Ethnography with the Oral History emphasizes analyzes on the relations constituted between the masters of art in miriti and the public entity Municipal, State and Federal perceived in the interpretations of the lived narrated by the masters. It aims to build interlocutions between the narratives of artisans and the epistemological proposal of cultural and postcolonial studies regarding the dialectic of cultural struggle and the reading of the historical process based on the daily experience of the different agents and their relations confrontations, entanglements, negotiations, and reciprocal lending. Finally, it points out the importance of understanding that in the culture the experience of the different subjects, or social groups, or institutions where these agents meet, exchange relations and sociability, strength and power within the framework of social practices built on a daily basis by men and women who make history happen and move the local and regional historical process.
\end{abstract}

Keywords: Amazon; Memory; Miriti; Job;

\title{
1. Palavras Iniciais
}

Os (as) trabalhadores (as) das artes em miriti de Abaetetuba são homens e mulheres paraenses que cortam, entalham, colorem e alinhavam formas culturais, criam possibilidades de relacionamento social e produtivo e tecem a história na Amazônia. Constituídos em processos de aprendizagens em circuito familiar, artesãos (ã) há gerações compartilham histórias, saberes, fazeres, alegrias, encantamento, lutas entretecem a existência superando dificuldades e limites da vida terrena. Mestre e mestra de miriti, narradores deste texto, são habitantes do Estado do Pará, particularmente do município de Abaetetuba.

O Município de Abaetetuba está geograficamente localizado na Amazônia, faz parte da região de Integração Tocantina, Mesorregião do Nordeste Paraense, Microrregião de Cametá. Abaetetuba, sede do município, é uma cidade ribeirinha localizada a margem direita do rio Maratauíra, afluente do estuário do Rio Tocantins, tipificada pelo sociólogo Jones Gomes (2013) como uma cidade da arte. No mapa 1, reproduzido abaixo, apresentamos a localização geográfica do município de Abaetetuba. 


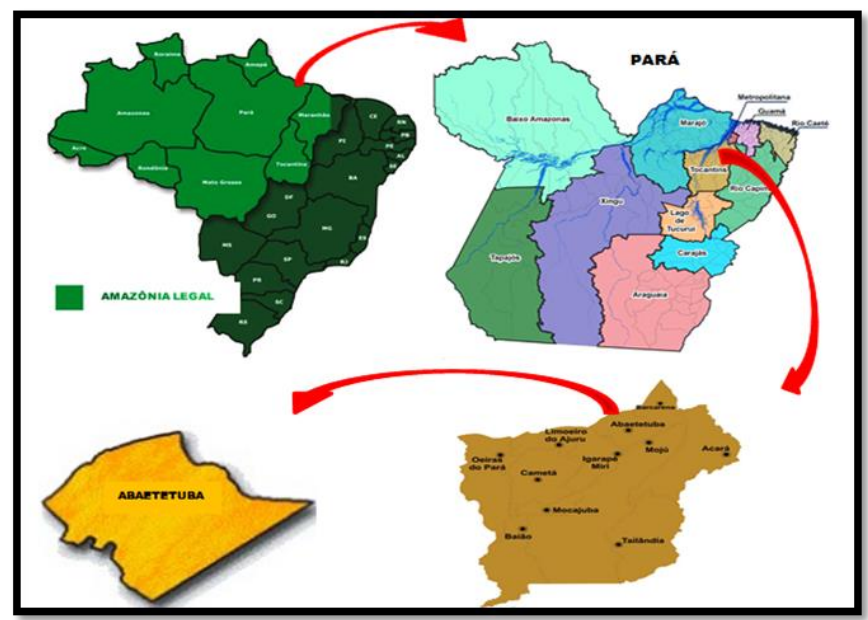

Mapa 1: Localização geográfica do município de Abaetetuba.

Fonte: imagens Google - montagem de Éverson Carlos Q. da Silva.

Inserido nas belezas artísticas e culturais engendradas por homens e mulheres abaetetubenses está o produto da habilidade manual e atividade laboral desenvolvida pelos (as) mestres (as) artesãos (ãs) de miriti. Das relações cotidianas entre trabalhadores (as) do miriti e a floresta, particularmente a palmeira Mauritia flexиosa, popular miritizeiro, se urdem memórias, entretecem-se saberes, expressam-se concepções, sonhos pessoais, coletivos e nutrem a dinâmica cultural e história local em profunda simbiose e agenciamentos com outras experiências globais. Apresenta-se a seguir a imagem da palmeira miritizeiro, capturada nas margens do Rio Maratauíra. Ao lado de outras palmeiras nativas da Amazônia a Mauritia flexuosa se destaca por sua altura.

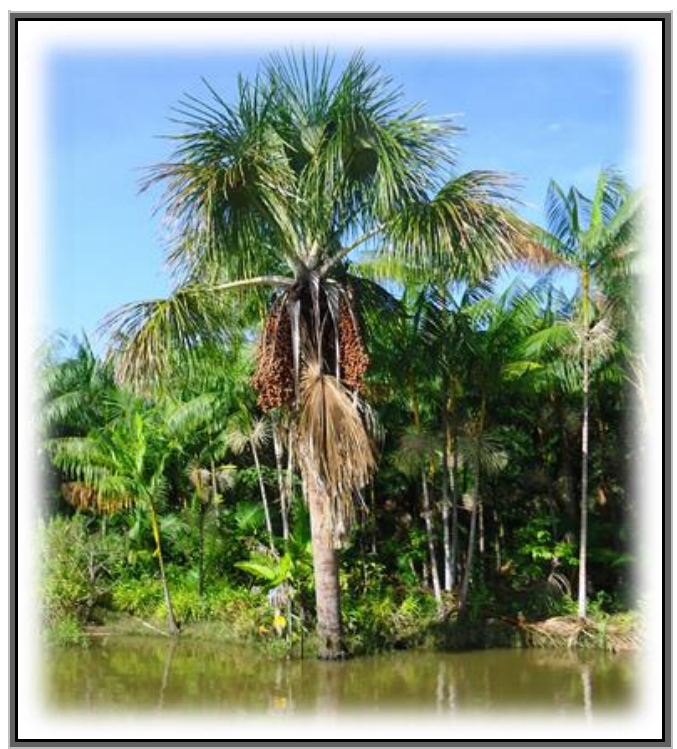

Fotografia 01: Palmeira Mauritia flexuosa.

Fonte: Arquivo Pessoal da pesquisadora. Pesquisa de Campo. Maio/2016.

Objetivamos neste paper apresentar parte das reflexões que estamos desenvolvendo na tese de doutoramento em História Social da Amazônia, intitulada Mestres 
da Memória: Aprendizagem, Trabalho e Economia nas Artes de Miriti (Abaetetuba-PA). Aqui nos deteremos analisar as relações constituídas pelos (as) mestres (as) e os entes público municipal, estadual e federal, percebidas nas suas narrativas em diálogo com a perspectiva epistemológica dos estudos culturais e pós-colonial no que tange a "dialética da luta cultural" proposta pelo sociólogo Stuart Hall (2003) e a leitura do processo histórico a partir da experiência cotidiana dos diferentes agentes e suas relações de confrontações, entrelaçamentos, negociações e empréstimos recíprocos.

Para atingirmos tal finalidade orienta-nos metodologicamente a história oral na concepção de Portelli (1997; 2016) em conexão com a etnografia proposta por Geertz (1989; 2005). Para Portelli (2016, p. 10; 12. Grifo do autor) a história oral é "primordialmente uma arte da escuta", a qual tem como fundamento um conjunto de relações, sendo a primeira delas o diálogo que envolve o vínculo de respeito, confiabilidade, troca de experiências e afetação entre entrevistador e entrevistado.

Geertz (1989), por sua vez, nos ensina a importância em se produzir a "descrição densa" entendida como uma descrição detalhada, minuciosa da realidade considerando o lugar, o tempo e os múltiplos sujeitos, com o objetivo precípuo de captar as teias de significados que envolvem a ação humana. Este autor nos recomenda, também, a atenção para a percepção da polifonia de significados e interpretações ao afirmar que "começamos com as nossas próprias interpretações do que pretendem nossos informantes, ou o que achamos que eles pretendem, e depois passamos a sistematizá-las" (GEERTZ, 1989, p. 13).

Desta forma, entendemos que a história oral e a etnografia se complementam para o estudo e compreensão de uma dada realidade, na medida em que ambas se preocupam nos processos de afetação entre pesquisador/entrevistador e pesquisado/entrevistado - o eu e o outro, ou seja, o pesquisador entra em contato com o universo dos pesquisados e compartilha seu horizonte construindo uma relação dialógica de troca de experiências. Se de um lado a história oral valoriza o processo de afloramento e construção da memória no ato da entrevista, por outro lado, a etnografia preocupa-se em observar todos os detalhes do cenário, captando os mais variados sentidos e significados. Assim, o viés teórico-metodológico proposto pela história oral e pela etnografia nos proporciona a inserção no trabalho cotidiano dos (as) artesãos (ãs) de miriti do município de Abaetetuba, buscando captar os movimentos, sociabilidades, relações, trocas, conflitos e negociações engendrados por este grupo de trabalhadores (as).

Estruturalmente, o texto está organizado em duas seções, somado as Palavras Iniciais e Finais. Na primeira seção, a qual se intitula Mestres (as) da Memória: Jeitos de Ser e 
Trabalhar, apresentamos o mestre artesão Célio e a mestra artesã Dorinha em suas vivências diárias, suas cosmovisões e jeitos de ser, viver, organizar, trabalhar, lutar, superar dificuldades, sonhar e como estes modos se relacionam com a composição de sua arte em miriti. Em seguida, entrelaçamos narrativas das vivências de organização e luta dos (as) mestres (as) e o pensamento da "dialética da luta cultural" sustentada por Hall (2003). Esta $2^{\mathrm{a}}$ seção tem como título Mestres (as) da Memória: mãos que talham a vida na Amazônia e fiam a História.

\section{Mestres (as) da Memória: um pouquinho de cada modo de Ser e Trabalhar}

Os (as) mestres (as) artesãos (ãs) são descritos (as) de várias formas em obras de diferentes segmentos literários. Eis alguns exemplos: para o romancista Leite (2009, p.9) "ele é a história das suas mãos".

Na narrativa do poeta Loureiro encontramos a seguinte caracterização (2012, p. $18 ; 19)$ :

É um artesão que tem a execução material de sua obra acompanhada de uma interação e um gesto estetizante em sua modelagem. É evidentemente possuidor de uma técnica apurada, a serviço de uma concepção de forma significante no contexto cultural em que está inserido. [...] Desnuda a polpa do miriti de sua veste de talas. Imprime nela uma forma econômica simples. A mesma mão que faz barcos de verdade, constrói casas, forja o ferro, navega e pesca, é a que imobiliza no miriti o acaso do seu devaneio. A mão do trabalho pesado fazendo o trabalho da leveza.

A convivência de décadas da professora Nazaré Lobato como esposa do mestre artesão Marinho, e seu olhar de escritora, permitiu que ela deixasse registrado em seus escritos que

O artesão, homem rústico, com o miriti em punho e a faca afiada nas mãos calejadas pelo labor, trabalha dando formas inusitadas aos pequenos e médios pedaços do produto excepcional, o qual entalhado com habilidade, surge em sua frente, transformados em tatus, cobras, pombinhas, soca-soca, barcos e outros, já caracterizados em brinquedos de miriti (LOBATO, 2011, p. 11).

A visão do romancista, do poeta e da professora/esposa reconstitui o cotidiano de trabalho de homens e mulheres que manejam a tradicional faquinha no encontro com a palma do miriti entalhando diferentes objetos. Constituídos em processos de aprendizagens em circuito familiar, artesãos e artesãs cotidianamente resistem, reconstroem-se, reinventam-se, ressignificam-se e afirmam-se pela arte em miriti. São pessoas que há gerações compartilham histórias, saberes, fazeres, alegrias, lutas pela vida e tecem a existência superando dificuldades e limites do viver. 
Para além dos olhares externos observados e registrados sobre o viver dos (as) trabalhadores (as) de miriti, está a interpretação de si, expressa pelos (as) próprios (as) mestres (as) artesãos (ãs). Seguimos a tessitura deste artigo deixando com que as suas próprias narrativas em aspectos do vivido, reconstruídos pela memória venham à tona.

Para adentrarmos aos territórios das experiências de vida e de luta dos (as) mestres (as) das artes em miriti pelos caminhos da História Oral, torna-se fundamental esclarecermos o conceito de memória que alicerça nossa análise. Nas últimas décadas, o fenômeno da memória como fonte viva de informações para o estudo de um dado momento histórico tem sido recorrente nas ciências sociais. Os estudiosos da contemporaneidade têm relacionado o conceito de memória à conservação, ao esquecimento e à seleção, interrelacionando-a com o contexto social. O sociólogo Halbwachs (2004) enfatiza em seus estudos o aspecto social e coletivo da memória, ou seja, para este pesquisador a memória é constituída por indivíduos em interação com outros membros do grupo ao qual pertence. Essa dimensão da memória como construção coletiva e social postulado por Halbwachs (2004) abriu portas para que outros autores agregassem novas análises. É o caso da proposição desenvolvida por Pollak (1992) que nos revela a dimensão conflitiva da memória.

Nas reflexões desenvolvidas por Pollak (1992, p. 5) a memória é "um fenômeno construído social e individualmente" inserido em um processo de conflito e disputa constante e de constituição do sentimento de identidade tanto individual como coletiva. Nesse sentido, entende-se que a memória individual tem a importante função de contribuir para o sentimento de pertinência a um grupo de passado comum, que compartilha memórias constituídas individual e coletivamente. A identidade se constitui nesta memória compartilhada, que é história viva e vivida no eterno presente e permanece no tempo renovando-se.

Seguindo os argumentos de Pollak (1992) concebemos a memória de homens e mulheres na lida com os saberes da arte em miriti não como mera conservação pura e integral do passado de cada indivíduo, mas como uma (re) construção deste realizada no presente que nos permite registrar olhares acerca de experiências de vida vivida individual e coletivamente.

Partindo desse pressuposto, nosso mergulho na história de vida inicia-se pelo mestre indicado por seus colegas de ofício, em pesquisa exploratória por mim realizada, como referência de artesão de miriti na feitura de pássaros pequenos para compor móbiles. Trata-se de Seu Célio Vilhena Ferreira. Nossos encontros para dialogarmos sobre seu trabalho com o miriti, deu-se nos eventos de exposição e comercialização e em sua residência. Quando me recebia em sua casa, no cômodo da oficina, sentado em seu banquinho de madeira, enquanto 
esculpia as palmas de miriti, aos poucos, ía abrindo o livro de sua vida para meus registros. Assim ele faz sua apresentação:

Meu nome é Célio, nasci em 26 de maio de 1958, no rio Belchior. Tenho 59 anos. Fui criado com meu pai João da Silva Ferreira e minha mãe Andrelina Vilhena Ferreira. Sou casado com a Orlanda Azevedo, temos 04 (quatro) filhos, 02 (duas) filhas e 06 (seis) netos. (Mestre artesão Célio V. Ferreira)

A imagem 02, exibida a seguir, foi escolhida por Mestre Célio para apresentá-lo no texto da tese a qual estamos construindo. Nela observa-se o mestre artesão segurando a pombinha talhada por ele ao lado de outros objetos de miriti, também, de sua autoria.

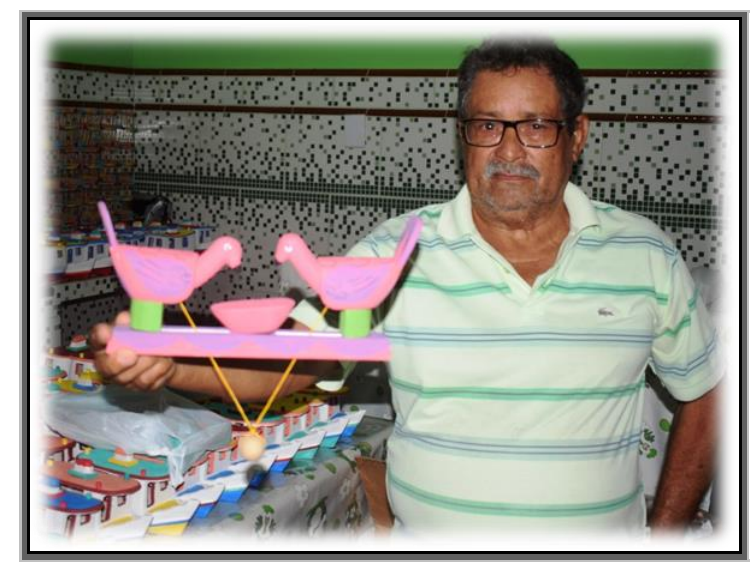

Fotografia 02: Mestre Célio Vilhena Ferreira em sua residência.

Fonte: Arquivo Pessoal da pesquisadora. Pesquisa de Campo. Maio/2017.

Sua infância foi vivida na zona rural de Abaetetuba (região das ilhas), sendo marcada pelo trabalho ao lado de seus pais, conforme nos relata:

Minha mãe era doméstica, cuidava da criação e das plantas. Meu pai era marreteiro de frutas, de criação, a gente ía lá pro Cuitininga e Camarãoquara apanhar jambo rosa, manga, comprar frutas, plantas, frango e, assim, ele dava 02 (duas) viagens por semana em Belém pra ir vender a mercadoria dele. Do miriti a gente fazia muito paneiro. Eu era molecote. [...] O miriti a gente ía pro mato e ajuntava, amolecia e a gente comia o miriti. Fazia o vinho, tomava o mingau. (Mestre artesão Célio V. Ferreira)

As expressões e gestos que acompanham a narrativa de Mestre Célio ao falar sobre as atividades laborais que já exerceu e exerce demonstram seu sentimento de realização pessoal e profissional como artesão de miriti. Acerca das memórias do trabalho, continua:

Minha profissão era carpinteiro, mas eu tinha um irmão que era artesão, é o Jadson, então ele falou pra mim: -"meu irmão larga isso faz tanto trabalho, trabalha como empregado, humilhado pro outro, vem trabalhar com artesanato". Aí eu larguei a profissão comecei a fazer brinquedo e deu certo, viu!!! Graças a Deus deu certo. Foi com ele que eu aprendi, eu tinha 34 (Trinta e quatro) anos.

Pra mim o miriti significa muita coisa, nem fale até! Porque é de onde eu vivo com minha família, graças a Deus. (Mestre artesão Célio V. Ferreira) 
Contentamento, gratidão e sonhos realizados e/ou a serem concretizados movem a vida deste narrador que compartilha conosco o que lhe é mais prazeroso fazer no trabalho com miriti, bem como, seu maior sonho material naquele momento. Conta Mestre Célio: "O que eu mais gosto de fazer é pássaro, devido ser uma peça pequena onde a gente tem como pegar e o meu forte é móbile, tirando isso é o barco. Esse ano eu vou levantar minha casa de alvenaria se Deus quiser. Meu sonho é esse".

Dos barquinhos que alegravam suas brincadeiras de infância aos pássaros que exprimem a beleza do seu fazer artístico, atravessando a labuta diária da experiência de viver em sociedade, pausamos essas memórias da vida de Mestre Célio com as palavras de Leite (2009, p. 85-86) "cada brinquedo guarda uma ternura. Basta olharmos para eles. Sentirmos a sua leveza em tudo. Ali há uma árvore. Uma gente. Um mundo. Uma vida”.

A leveza, a ternura, o sonho, o amor, a batalha personificada em cada objeto artístico de miriti fazem emergir conexões entre pessoas que vivem distantes territorialmente, mas que se encontram na luta pela construção de um ideal comum. Assim se cruzam a vida do Mestre Célio e da Mestra Dorinha.

Na imagem 03 observa-se a artesã na sala de sua residência, sentada em uma cadeira plástica, manuseando um pincel e utilizando tintas de várias cores, está pintando e finalizando o acabamento de uma barquinha. Ao seu lado encontra-se uma mesa de madeira na qual a artesã organiza os pincéis e os potes de tinta de cores variadas. No chão, à sua frente, e embaixo da mesa, ao seu lado, ela organiza os brinquedos para secagem e depois embalagem para comercialização.

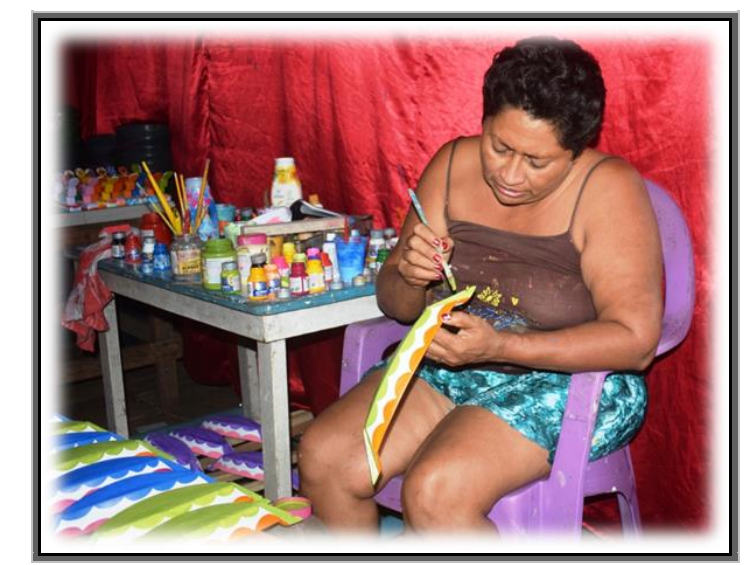

Fotografia 03: Artesã Dorielma do S. C. Cardoso - Mestra Dorinha. Fonte: Arquivo Pessoal. Pesquisa de Campo Janeiro /2017.

Nesse ambiente familiar, fui recebida várias vezes por Mestra Dorinha para conversarmos sobre seu trabalho com o miriti. Na pesquisa exploratória, Mestra Dorinha foi indicada pelos demais colegas de ofício como conhecedora e executora de todas as etapas do 
processo de feitura das artes em miriti, desde a extração da matéria prima até a venda do produto final. Em nosso diálogo assim a artesã se apresenta:

Eu me chamo Dorielma do Socorro Carvalho Cardoso, conhecida Dorinha. Nasci no dia 03 de agosto de 1969, na Vila Maiauatá. Meu pai era Miguel A. de Carvalho. Ele era viajante/comerciante. Minha mãe Maria de Nazaré F. Carvalho sempre trabalhou em casa de família e era lavadeira. (Mestra artesã Dorinha)

Mestra Dorinha nos conta as dificuldades enfrentadas, as quais inviabilizaram a conclusão de sua formação acadêmica na Educação Básica e lhe forçaram a iniciar suas atividades laborais ainda na infância:

Iniciei a estudar com sete anos no Vicente Maués [...] eu não concluí porque minha mãe trabalhava e meu pai separou da minha mãe, aí ficou só nós três eu, minha irmã e minha mãe que trabalhava pra nós. Ficava cansativo, ela lavava muita roupa pra fora, era muita roupa. Aí eu comecei a trabalhar em casa de família, com 12 anos, pra ajudar. [...] A gente trabalhava de segunda a sábado e quando chegava no fim de semana a gente não tinha condições de sair [...]tinha que trabalhar pra adquirir o sustento. (Mestra artesã Dorinha)

Aos 13 anos de idade a artesã conheceu o mestre artesão Santinho, iniciaram um relacionamento que perdura até os dias atuais. $\mathrm{O}$ início desse romance e a formação de sua família são narrados por Mestra Dorinha:

Olha [...] a tia dele era casada com o irmão da minha mãe [...] Aí a gente se conheceu e deu certo, a gente casou. Nós casamos em 1985, no dia 21 de setembro. Nos conhecemos três anos antes. Aí depois que eu me casei, com 16 anos, eu já parei de trabalhar fora, em casa de família. [...] Aí eu fui tendo os filhos e naquela época eu nunca gostei de tomar remédio pra evitar filho. Eu era muito nova, engravidei e tive 07 (sete) filhos. Eu tive um atrás do outro logo, [...] o mais velho tá com 33 anos (trinta e três) e o caçula com 21(vinte e um) anos de idade. (Mestra artesã Dorinha)

Mestra Dorinha deixa o trabalho em outras residências e passa a assumir as atividades domésticas de sua própria casa e a dedicar-se aos cuidados de mãe junto aos filhos e filhas. Ao rememorar esta fase jovial de sua vida, a artesã sente-se gratificada, pois, mesmo tendo vivido muitas dificuldades, conseguiu com esforço, junto com seu esposo Santinho e o auxílio de sua mãe e irmã, criar seus sete filhos.

Atualmente, Mestra Dorinha continua dividindo seu tempo entre as várias atividades laborais que executa, são elas: tarefas domésticas, serviço de buffet que oferece para atender qualquer tipo de evento e o artesanato em miriti. Destas atividades ela nos fala qual desenvolve com maior gosto e satisfação: "as minhas coisas preferidas são cozinhar e pintar brinquedos. Gosto muito". 
Com seu jeito singular de ser e estar neste mundo, Mestra Dorinha é artesã, mulher empreendedora, sonhadora e lutadora. Pretende expandir seus negócios, especializarse para servir às pessoas com deliciosas comidas e belos artesanatos de miriti e assim demarcar e conquistar espaço de mestra artesã. Luta ao lado e junto com outras artesãs pelo empoderamento da mulher e pela valorização do artesanato de miriti.

Em últimas palavras, as narrativas autobiográficas lembradas, selecionadas e compartilhadas pelo (a) mestre (a) artesão (ã) configuram seus rostos, cosmovisões, caráter, maneiras de ser, viver, crer, sonhar, lutar, enfim, retomo as palavras de Loureiro "A mesma mão que faz barcos de verdade, constrói casas, forja o ferro, navega e pesca, é a que imobiliza no miriti o acaso do seu devaneio". A mão do trabalho pesado fazendo o trabalho da leveza. (LOUREIRO, 2012, p.19).

No próximo item ampliaremos a discussão acerca dos trabalhos realizados por Mestre Célio e Mestra Dorinha, abordando as estratégias de luta, de organização, de entrelaçamentos, os circuitos de trânsito e ideias que perpassam o trabalho da leveza dos (as) mestres (as) de miriti.

\section{Mestres (as) da Memória: mãos que talham a vida na Amazônia e fiam a História}

Iniciamos a escritura deste item com uma narrativa da mestra Dorinha falando sobre como faz sua escolha dos tipos de brinquedos para confeccionar e levar a uma exposição e venda.

Tem que ter os tradicionais: a cobra, a casinha, a pombinha, o tatu, o barco, o soca-soca, o pila-pila, ... Esses tem que levar, né? que são os tradicionais, agora cada ano que passa a gente tem que fazer uma inovação. Se o cliente chega na feira ele pergunta: o que é que tem de novidade esse ano? Então, a gente procura inovar cada ano que passa. (Mestra artesã Dorinha, grifo nosso).

Complementamos a narrativa com uma fotografia capturada no XV Festival do Miriti (MIRITIFEST). A imagem 04 apresenta o stand, organizado no citado evento, com os objetos de arte em miriti produzidos por Mestra Dorinha e seu esposo Mestre Santinho. Nela podem-se observar diversos elementos que compõe o cotidiano e formam o universo cultural abaetetubense: vários tipos de pássaros (tucano, papagaio, arara, etc.); diversas profissões (soca pilão, pescador e vendedor ribeirinho); meios de transporte aquático (canoa e barco); casal de namorados, personagens de programas televisivos, adereços religiosos, dentre outros. 


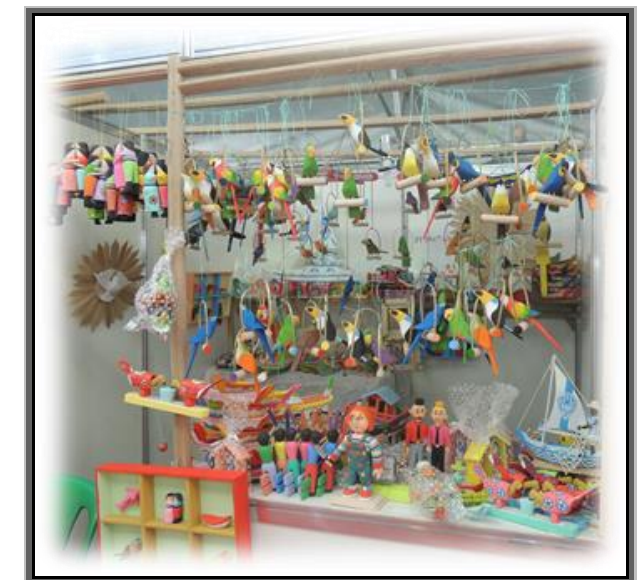

Fotografia 04: Exposição e venda de artesanatos de miriti. Evento: XV MIRITIFEST / 2018.

Fonte: Arquivo Pessoal. Pesquisa de Campo Maio /2018.

À luz dos pressupostos teóricos desenvolvidos por pesquisadores dos Estudos Culturais e Pós-colonial, a narrativa e a fotografia 04, nos possibilitam notar através da cultura o processo histórico de constituição e significação da vida social, pois no trabalho de transformação da matéria-prima miriti em objetos de arte, mestres (as) artesãos (ãs) criam, expressam seus olhares a cerca da realidade e atribuem sentido e significado a sua existência tornando-a possível.

Pactuamos com a ideia de cultura proposta por Hall (1997, p. 1) na qual o autor afirma que "os seres humanos são seres interpretativos, instituidores de sentido", portanto, criam "sistemas ou códigos" para organizar e regular o relacionamento entre si. Para este autor, o conjunto de "sistemas ou códigos que dão sentido às ações humanas" e possibilitam "interpretar significativamente as ações alheias" formam "as culturas". Em outras palavras, a cultura para Hall (2003, p. 142, grifos do autor) se define

Ao mesmo tempo como os sentidos e valores que nascem entre as classes e grupos sociais diferentes, com base em suas relações e condições históricas, pelas quais eles lidam com suas condições de existência e respondem a estas; e também como as tradições e práticas vividas através das quais esses "entendimentos" são expressos e nos quais estão incorporados.

$\mathrm{Na}$ esteira desse pensamento, entendemos que a prática social engendrada pelos (as) mestres (as) artesãos (ãs) de miriti tem uma dimensão cultural por englobar um conjunto de conhecimentos, modos de fazer, criar, expressar, relacionar-se, sentir e pensar, construído cotidianamente por cada um (a) em suas relações sociais com outros (as) sujeitos (as) humanos (as) e não humanos (as), constituindo sentido à existência individual e coletiva e (re) produzindo o mundo social e cultural amazônico abaetetubense. Com essa compreensão, 
consideramos a narrativa da Mestra Dorinha e a imagem 03 das artes confeccionadas por ela, exemplificadoras nesse processo de (re) fazer-se.

Conceber a cultura como o resultado das experiências vivenciadas por todos os indivíduos, independente da posição social e política e do espaço territorial que ocupam, implica abrir-se à pluralidade de modos de viver existentes no planeta. Significa, ainda, como bem assinala Hall (1997), falar em culturas, não em cultura, que são construídas em contextos diversos, com dinâmicas diferenciadas e que devem ser compreendidas no interior de sua edificação e de seu tempo histórico.

Visto desse modo, inexiste a distinção classificatória hierarquizada e dicotômica entre culturas ditas superiores e inferiores, melhores e piores, civilizadas e não civilizadas, evoluídas e atrasadas e tantos outros adjetivos usados quando se tem como referência uma única forma padrão de experienciar a vida na Terra.

Portanto, na lógica da heterogeneidade cultural não existe um ponto de referência, mas pontos de convergências que se entrecruzam e fazem desabrochar pelas culturas a beleza do ato de (re) criação humana, a exemplo das artes em miriti que vemos na fotografia 3 na qual se percebe elementos naturais que fazem parte da vida amazônica, como os pássaros, o ribeirinho vendedor, ao lado de elementos que ingressam no cotidiano dos (as) mestres (as) por meio virtual, são ressignificados e passam a compor sua realidade, como o personagem televisivo Chuck.

Dentro desse contexto, vemos que os (as) artesãos (ãs) das artes em miriti acompanham e integram-se aos processos hegemônicos globalizadores, interagem com outros modos de viver e, por conseguinte, valendo-se dos conhecimentos herdados de seus antepassados, os saberes adquiridos na convivência com a floresta, o rio e sua comunidade, agregam novas práticas, técnicas e outras formas, recriam e renovam sua obra de arte, fruto de seu trabalho. Em outras palavras, entendemos que este grupo de trabalhadores (as) constroem a pluralidade e heterogeneidade das manifestações culturais do Brasil, acrescentando a ela o caráter lúdico, a alegria e o encantamento.

Cabe acrescentar e enriquecer esta análise com as contribuições do filósofo Garcia Canclini (2008) quando faz uma análise da nova organização da sociedade capitalista globalizante e aponta o consumo como fator de construção de uma marca de pertencimento. Ao consumir bens materiais ou simbólicos, mais do que ser enquadrados como vorazes consumidores de superficialidades e objetos de manipulação da economia capitalista, os consumidores estariam tecendo as malhas do tecido social a que pertencem ou desejam pertencer, criando sua identidade. 
Os meios de comunicação fazem circular signos, por códigos de identificação que nos unificam, e, mesmo quem nunca saiu de seu país, se faz entender, pelo fato de compartilhar alguns signos, logotipos, ídolos e outros elementos da sociedade e da cultura. Tal visão implica conceber o mundo não mais como simples lugar de comercialização de produtos, mas também como parte de interações socioculturais complexas. Implica considerar ainda, que as identidades culturais são uma construção híbrida, formada por elementos mesclados de várias culturas.

Ao nosso olhar, as análises de Canclini (2008) podem se percebidas na narrativa da Mestra Dorinha, reproduzida no início deste item, ao mencionar o cliente como impulsionador da inovação dos produtos. Vemos, ainda, as reflexões deste autor materializadas na fotografia 04 , quando se observa confeccionados com a matéria prima miriti bonecos midiáticos, bem como, miniaturas de animais característicos da fauna Amazônica.

Nessa matriz epistemológica de compreensão da cultura como uma rede de interconexões com as demais dimensões da vida humana, em processo contínuo de significação e ressignificação, uma dinamicidade própria de cada agrupamento humano, há de se atentar para as relações de força e poder que perpassam as interações sociais.

Compreendemos que na cultura a experiência dos diferentes sujeitos, ou grupos sociais, ou instituições onde os agentes se encontram, travam relações sociais de confronto, de trocas, de entrelaçamentos, entre todas as práticas sociais construídas no dia a dia por homens e mulheres. Estes relacionamentos, naturalmente conflituosos, fazem a história acontecer e movimentam todo o processo histórico.

Nesse sentido, retomamos as reflexões de Hall $(1997,2003)$ ao considerar a centralidade da cultura e sua complexidade para a compreensão do processo histórico e as transformações da vida local e cotidiana, este autor ressalta que "[...] dentro da 'cultura' todas as práticas interagem - ainda que de forma desigual e mutuamente determinante" (2003, p. 142), ou melhor, o campo da cultura é um lugar de luta permanente entre os diferentes grupos, no qual não se consegue vitórias definitivas, mas há sempre perdas e ganhos, "posições estratégicas a serem conquistadas ou perdidas. Esta é a dialética da luta cultural" (2003, p. 255).

As palavras da Mestra Dorinha, abaixo descritas, nos permitem continuar dialogando com as proposições de Hall (1997, 2003), especificamente com essa ideia da dialética da luta cultural. Acerca da relação e participação do poder público para a melhoria do trabalho dos artesãos de miriti, Mestra Dorinha faz sua avaliação e nos diz: 
O município tem uma parte assim que eles ajudam entre aspas, mas têm muitas outras que eles deixam a desejar, eu vejo assim. $O$ nosso Miritifest aqui de Abaetetuba foi criado e foi uma grande vitória, né? Quando foi feito a primeira vez o Miritifest que a gente fez com a cara e a coragem, o Prefeito Chico Narrina falou: dei ou não dei certo a gente vai fazer. Foi na Praça de Conceição a primeira vez, o primeiro ano e sucessivamente foi acontecendo, né? Mas muitas coisas já estão deixando a desejar, porque eu acho que o nosso município, assim os governantes (Vereadores e Prefeito) uma coisa que eles deveriam priorizar é a questão da divulgação do nosso Miritifest, porque nos primeiros anos que foi feito, foi bem divulgado. A divulgação é a alma do negócio, infelizmente hoje se você tiver um negócio e não saber divulgar, você não vende. [...]. Quando foi feito uma divulgação $100 \%$, foi muito bom. (Mestra artesã Dorinha, grifo nosso).

Prossegue sua narrativa e posicionamento apontando caminhos e possibilidades de melhorias para a continuidade do trabalho,

Aí a mesma coisa da Feira do Círio em Belém, ela não tá sendo bem divulgada. [...] uma divulgação internacional, os nossos gestores têm condição. Hoje a internet tem uma habilidade, o próprio site da prefeitura pode jogar isso, entendeu? Mas o que falta? É os nossos gestores ajudar. (Mestra artesã Dorinha, grifo nosso).

Penso que há interligações entre essas falas de Mestra Dorinha e a proposta de Hall (2003), ao referir-se que a criação do Miritifest foi uma vitória, mas que não está sendo prioridade na política cultural desenvolvida pelos governantes, ao propor que os gestores públicos assumam a sua parte na organização da Feira do Círio, demonstram que o palco da cultura é um lugar de constantes e contínuas tensões e disputas entre projetos, estratos e forças sociais, no qual há sempre perdas e ganhos. Em suma, nos dizeres de Hall (2003, p. 262) a cultura é a "arena do consentimento e da resistência".

Avançando em nossas análises assentadas nas reflexões de Hall (1997; 2003), acrescentamos abaixo mais uma narrativa do Mestre Célio a qual julgamos ser significativa nesta tessitura. Mestre Célio, ao perceber a necessidade e importância de se unir a outros mestres e se organizar enquanto categoria para atingir objetivos comuns ao ofício tornou-se fundador e sócio da Associação dos Artesãos de Brinquedos e Artesanatos de Miriti de Abaetetuba (ASAMAB). Ao se reportar e comparar suas condições de trabalho na Feira do Círio de Nossa Senhora de Nazaré em Belém, antes e depois da Associação, bem como os agenciamentos construídos com outras entidades, diz o artesão:

A associação é muito importante. Porque a gente, de primeiro, ía para Belém nós era parece um mendigo. Ía com aquele bocado de material. Levava o plástico, fazia a casa naquela praça. E agora não, é cobertura mesmo especial que a gente fica embaixo, eles ${ }^{3}$ fazem a feira com a gente tudo organizado mesmo, então a gente não fica mais como mendigo, melhorou muito, muita coisa melhorou pra nós, artesãos.

\footnotetext{
${ }^{3}$ Refere-se aos órgãos públicos e entidades privadas que organizam os eventos em parceria com a ASAMAB.
} 
Quando a gente não tinha associação a gente não ía, por exemplo, no Banco do Brasil, na Caixa Econômica deixar um papel pra eles ajudarem nós. E agora não, é só a gente ir lá que é bem atendido mesmo, graças a Deus e ao SEBRAE. (Mestre artesão Célio V. Ferreira)

Essa narrativa do Mestre Célio nos parece esclarecedora quando dialogamos com o argumento de Hall (2003) acerca da dialética da luta cultural, na medida em que juntar-se e constituir juridicamente uma entidade representativa dos (as) artesãos (ãs) de miriti acreditamos que se configura em uma estratégia desse grupo de trabalhadores, no campo de lutas e relações de poder, visando ampliar suas conquistas construindo teias de relacionamentos e influência como entidade civil, favorecendo o fortalecimento e continuidade do ofício no interior da sociedade capitalista globalizada.

Outra coisa importante de dizer que complementa a dita acima é que nessa relação e jogo de poder observa-se ao lado do consentimento a resistência, pois se a infraestrutura física padronizada aos moldes comerciais capitalistas foi aceita positivamente pelos (as) artesãos (ãs), como avalia mestre Célio, por outro lado o enquadramento nas regras do mercado parece não ter sido bem recebido, conforme podemos notar na narrativa a seguir:

[...] as regras do Sebrae prejudicou a venda do brinquedo de miriti, porque o brinquedo ele tem que tá exposto no amplo pra quando o turista chegar ele ficar a vontade. Aquelas frescuras do Sebrae não é pra nós, pro nosso brinquedo, infelizmente. Tem horário fechado e o nosso público ele é aleatório. (Mestra artesã Dorinha, grifo nosso)

Observa-se com essa narrativa da Mestra Dorinha que nas complexas relações culturais que envolvem forças de poder e dominação

[...] as pessoas comuns não são uns tolos culturais, eles são perfeitamente capazes de reconhecer como as realidades da vida da classe trabalhadora são reorganizadas, reconstruídas e remodeladas pela maneira como são representadas (isto é, reapresentadas [...] (HALL, 2003, p. 254)

Enfim, pausamos esta breve análise reafirmando que é dessa maneira que mestres (as) artesãos (ãs) de miriti são agentes históricos, sujeitos e testemunhas da passagem do tempo experienciado em um trabalho de fazer e refazer artístico que compõe a pluralidade cultural amazônica. Nessa relação, fortalecem os vínculos culturais e tecem o complexo cotidiano amazônico, pois se por um lado sociabilidades, práticas de entreajuda e solidariedade alinhavam experiências de vida, por outro, tais experiências, no universo da floresta e do trabalho, se fazem também em exercícios de exploração, violência, precários serviços públicos (MARCON, 2003). 


\section{Palavras Finais}

Vimos que a cultura se encontra entrelaçada com todos os aspectos da vida em sociedade incluindo as interseções que se manifestam em outros campos. Esta compreende um conjunto de sentidos e significados, valores e padrões produzidos, transmitidos e recebidos em contextos sócio-históricos, nos quais estão implicadas relações de poder e conflito. Atualmente com a interligação de um mundo globalizado, a diversidade cultural persiste e se prolifera numa multiplicidade de maneiras de reunir identidades culturais. Cada agrupamento de homens e mulheres em suas experiências cotidianas cria cultura e contribui para expressar possibilidades do mundo humano, o qual não se realiza sem que nele apareçam contradições.

Nesse contexto, inserem-se os (as) mestres (as) artesãos (ãs) de miriti, os (as) quais, com sua habilidade artística e criadora, compõe a diversidade cultural Amazônica. Detentores de saberes de um ofício tradicional na Amazônia, mestres (as) da arte em miriti, em circuitos de tradições orais reproduzem e traduzem cotidianamente, no âmbito das práticas sociais construídas, relações de trabalho, aprendizagens, comercialização, sociabilidades, conflitos, força, poder e, assim, fazem a história acontecer movimentando o processo histórico local e regional.

Ao fim e ao cabo, o colorido do miriti e seu lugar como marca da identidade pessoal e da cultura local, mostra-se, nas narrativas, não se deixar ofuscar pelos tempos cinzentos que todos nós, especialmente de classes sociais de baixo poder econômico, enfrentamos. Enfim, a continuidade da pesquisa, o aprofundamento e ampliação das leituras nos permitirão avançar nas análises e, na tese, construir outras conexões possíveis com as memórias selecionadas e compartilhadas pelos (as) mestres (as) das artes em miriti da Amazônia.

\section{Referências Bibliográficas}

GARCÍA CANCLINI, Néstor. Consumidores e cidadãos: conflitos multiculturais da globalização. 7 ed. Rio de Janeiro: Editora da UFRJ, 2008. (Obra completa)

GEERTZ, Clifford. Uma Descrição Densa: Por uma Teoria Interpretativa da Cultura. In: A Intepretação das Culturas. Rio de Janeiro: Guanabara Koogan, 1989, p. 13-41. (Capítulo de Livro)

Estar Lá: A Antropologia e o Cenário da Escrita. In: Obras e Vidas: o Antropólogo Como Autor. Tradução Vera Ribeiro. 3. ed. Rio de Janeiro: UFRJ, 2005, p. 11-39. (Capítulo de Livro) 
GOMES, Jones da Silva. Cidade da Arte: uma poética da resistência nas margens de Abaetetuba. Tese (Doutorado em Sociologia), Universidade Federal do Pará, Instituto de Filosofia e Ciências Humanas, Programa de Pós-Graduação em Ciências Sociais, Belém, 2013. (Tese)

HALBWACHS, Maurice. A Memória Coletiva. Tradução de Laís Teles Benoir. São Paulo: Centauro, 2004. (Obra completa)

HALL, Stuart. Estudos Culturais: dois paradigmas. In. Da Diáspora: identidades e mediações. Tradução Adelaine La G. Resende [et.al.]. Belo Horizonte: Editora: UFMG. Brasília: Representação da Unesco no Brasil, 2003. P. 131-159. (Capítulo de Livro)

Notas sobre a Desconstrução do "Popular". In. Da Diáspora: identidades e mediações. Tradução Adelaine La G. Resende [et.al.]. Belo Horizonte: Editora: UFMG. Brasília: Representação da Unesco no Brasil, 2003. P. 248-264. (Capítulo de Livro).

A centralidade da cultura: notas sobre as revoluções culturais do nosso tempo. Revista Educação e Realidade, Porto Alegre: v. 22, no . 2, jul./dez. 1997. ISSN 2175-6236 (versão online). Disponível em: https://seer.ufrgs.br/educacaoerealidade/issue/view/3030/showToc. Acesso em: 10 Mar. 2015. (Artigo em Periódico Digital)

LEITE, Daniel da R. Girândolas. Belém: IOEP, 2009. (Obra completa)

LOBATO, Maria de Nazaré C. Nossa Arte, Nossa Vida. Abaetetuba, 2001. [S.I. - s.n.]. (Obra completa)

LOUREIRO, João de J. P.; OLIVEIRA, Jarbas. Da cor do norte: brinquedos de miriti. Fortaleza: Lumiar Comunicação e Consultoria, 2012. (Obra completa)

MARCON, Telmo. Memória, história e cultura. Chapecó: Argos, 2003. (Obra completa)

POLLAK, Michael. "Memória e identidade social". Estudos Históricos, Rio de Janeiro: v. 5, n.10, p. 200-212,1992. ISSN (versão online): 2178-1494. Disponível em: http://bibliotecadigital.fgv.br/ojs/index.php/reh/issue/view. Acesso em 16 Ago. 2010. (Artigo em Periódico Digital)

PORTELLI, Alessandro. História Oral como Arte da Escuta. Tradução Ricardo Santiago. São Paulo: Letra e Voz, 2016. (Obra completa).

O que faz a História Oral diferente. Projeto História, SP: Educ, v. 14, p. 25-39

Jan./Jun. 1997. ISSN 2176-2767 (versão online). Disponível em: http://revistas.pucsp.br/revph/issue/view/788/showToc (Artigo em Periódico Digital) 